\title{
Mechanical Parameters and Post-Cracking Behaviour of HPFRC according to Three-Point and Four-Point Bending Test
}

\author{
Francesco Bencardino \\ Department of Civil Engineering, University of Calabria, Via P. Bucci, Cubo 39/B, 87036 Rende, Italy \\ Correspondence should be addressed to Francesco Bencardino; f.bencardino@unical.it
}

Received 7 September 2012; Revised 2 September 2013; Accepted 16 September 2013

Academic Editor: Ashraf F. Ashour

Copyright ( 2013 Francesco Bencardino. This is an open access article distributed under the Creative Commons Attribution License, which permits unrestricted use, distribution, and reproduction in any medium, provided the original work is properly cited.

\begin{abstract}
High performance fibre reinforced concrete (HPFRC) is a modern structural material with a high potential and with an increasing number of structural applications. Structural design of HPFRC elements is based on the post-cracking residual strength provided by fibre reinforcement, and for structural use, a minimum mechanical performance of HPFRC must be guaranteed. To optimize the performance of HPFRC in structural members, it is necessary to establish the mechanical properties and the post-cracking and fracture behaviour in a univocal and reliable way. The best test methodology to evaluate the post-cracking and toughness properties of HPFRC is the beam bending test. Two different types of configurations are proposed: the three-point and the fourpoint bending tests. The overall focus of this paper is to evaluate the mechanical properties and the post-cracking and fracture behaviour of HPFRC, using the two different standard test procedures. To achieve these aims, plain and fibre concrete specimens were tested. All the test specimens were extensively instrumented to establish the strength properties, crack tip and crack mouth opening displacement, and post-cracking behaviour. The results of the two types of bending tests were critically analysed and compared to identify and highlight the differing effects of the bending load configurations on the mechanical parameters of HPFRC material.
\end{abstract}

\section{Introduction}

High performance fibre reinforced concrete (HPFRC) is a composite material characterized by a cement matrix and discrete fibres. Fibres are active as soon as microcracks are formed in the concrete. The main advantage of adding fibres to concrete is that they generate a post-cracking residual tensile strength in combination with a large tensile strain. As such, the fibre reinforced concrete (FRC) and the HPFRC are characterized by substantial ductility and toughness.

It is well known that the use of an adequate amount and an appropriate shape of steel fibres increases the tensile strength and the ductile behaviour of the concrete matrix. As the fibre volume content increases, the compressive [1-3] and the tensile post-peak behaviour improve as well as a greater fracture energy can be observed [4-6].

To optimize the structural design of HPFRC members, it is essential to know the mechanical and fracture properties of the material. These properties have to be evaluated on standard specimens and with standard recommendations. In the past, various types of specimens, testing procedures, and parameters have been proposed to analyse the postcracking behaviour in tension and toughness properties; as a result, some aspects were debated and revised by scientific and technical committees. With the purpose of establishing standard procedures, many national and international technical committees published several standards on concrete reinforced with steel fibres. The main standards available in the recent literature are RILEM TC 162-TDF [7-9]; UNI 11039-1 [10]; UNI 11039-2 [11]; ASTM C 1550 [12]; ASTM C 1609 [13]; ASTM C 1399 [14]; EN 14651 [15]. The most common experimental test set up for post-cracking and toughness measurement is the beam bending test carried out on beams with a notch at the tensile side [16]. Recently, the European Committee has proposed a three-point bending test procedure, while the Italian Committee has suggested a four-point bending test configuration. Furthermore, the recent guidelines CNR-DT 204 [17] and Fib 55 [18] have 
proposed, for analysis and design of FRC (or HPFRC) structural members, stress-opening and stress-strain relationship in uniaxial tension identified by means of four-point and three-point bending tests, respectively. Nevertheless, recent literature $[19,20]$ underlines how the scientific community is still debating to single out the best bending test between the two configurations and/or to define a relationship between them.

By using the beam bending test, that is, the most common experimental test set, the post-cracking tensile behaviour of HPFRC materials has been analysed in this work. Two types of configurations have been recommended by the main standards, such as the three-point bending tests (EN 14651 [15]) and the four-point bending tests (UNI 11039-2 [11]). With reference to these standards, experimental bending tests were carried out on HPFRC notched beams with the following goals:

(i) to evaluate the contribution of the fibres with high aspect ratio to the post-cracking behaviour of the high strength concrete;

(ii) to evaluate the mechanical properties and the postcracking behaviour of the HPFRC by using the two bending test methodologies;

(iii) to compare the main results obtained by using the two different standard procedures with particular reference to the mechanical parameters that are used in structural design.

\section{Research Significance}

With reference to HPFRC prismatic notched specimens, the experimental and analytical results obtained with three-point bending tests, according to EN 14651 [15], and those obtained with four-point bending tests, according to UNI 11039-2 [11], are critically examined. The purpose of this work is to analyse and compare the obtained results with reference to peak load, post-peak behaviour, and residual strengths, also highlighting the fibre contribution in mode I fracture behaviour with respect to the plain concrete (PC) matrix.

The comparison among the main mechanical parameters evaluated by using the two standard recommendations allows to point out the differences in defining the structural design parameters of the HPFRC. Furthermore, ductility indexes of the HPFRC useful in structural design were evaluated.

\section{Test Program}

3.1. Specimens. The experimental analysis was carried out on PC and HPFRC, cube and notched prismatic specimens. The adopted volume fraction of dramix steel (DS) fibres was $1 \%$ and $2 \%$. Compressive tests as well as three-point and fourpoint bending tests were carried out to highlight the role of the steel fibres with high aspect ratio on the compressive and tensile behaviour, respectively.

A generic group of HPFRC specimens has the following label type: DS1\% and DS2\% for specimens with $1 \%$ and $2 \%$ of
TABLE 1: Mixture proportions per $1 \mathrm{~m}^{3}$ of PC and HPFRC concrete.

\begin{tabular}{lccccc}
\hline \multirow{2}{*}{ Material } & \multirow{2}{*}{ Symbol } & \multirow{2}{*}{ Unit } & \multirow{2}{*}{ PC } & \multicolumn{2}{c}{ HPFRC } \\
& & & & DS1\% & DS2\% \\
\hline Cement & c & $(\mathrm{kg})$ & 500 & 500 & 500 \\
\hline \multirow{2}{*}{ Quartz } & $0 / 2 \mathrm{~mm}$ & $(\mathrm{~kg})$ & 406 & 406 & 406 \\
& $3 / 6 \mathrm{~mm}$ & $(\mathrm{~kg})$ & 294 & 294 & 294 \\
\hline \multirow{4}{*}{ Coarse aggregate } & $0 / 5 \mathrm{~mm}$ & $(\mathrm{~kg})$ & 540 & 462 & 383 \\
& $5 / 10 \mathrm{~mm}$ & $(\mathrm{~kg})$ & 222 & 222 & 222 \\
& $10 / 15 \mathrm{~mm}$ & $(\mathrm{~kg})$ & 240 & 240 & 240 \\
\hline \multirow{2}{*}{ Fibre } & $V_{f}$ & $(\%)$ & 0 & 1 & 2 \\
& - & $(\mathrm{kg})$ & - & 78 & 157 \\
\hline \multirow{2}{*}{ Silica fume } & $\mathrm{sf} / \mathrm{c}$ & $\%$ & 5 & 5 & 5 \\
& - & $(\mathrm{kg})$ & 25 & 25 & 25 \\
\hline \multirow{2}{*}{ Superplasticizer } & $\mathrm{sp} / \mathrm{c}$ & $\%$ & 1.5 & 1.5 & 1.5 \\
& - & $(\mathrm{kg})$ & 7.5 & 7.5 & 7.5 \\
\hline \multirow{2}{*}{ Water } & $\mathrm{w} / \mathrm{c}$ & - & 0.35 & 0.35 & 0.35 \\
& $\mathrm{w}$ & $(\mathrm{l})$ & 175 & 175 & 175 \\
\hline \multirow{2}{*}{ f } & & & & &
\end{tabular}

fibre content (percentage by volume), respectively. While for ordinary concrete, the label PC is used.

3.2. Materials and Mix Design. The concrete components were the following: Portland cement ASTM type I, crushed coarse aggregates, spherical quartz sand, water, condensed silica fume, and superplasticizer. The maximum size of the coarse aggregates was $15 \mathrm{~mm}$. The steel fibres had hooked ends, a tensile strength of $1050 \mathrm{MPa}$, a length $\left(L_{f}\right)$ of $50 \mathrm{~mm}$, and an aspect ratio of 80 . The specific gravity of each component was cement $3.15 \mathrm{~g} / \mathrm{cm}^{3}$, quartz aggregate $2.65 \mathrm{~g} / \mathrm{cm}^{3}$, silica fume $2.2 \mathrm{~g} / \mathrm{cm}^{3}$, superplasticizer $1.15 \mathrm{~g} / \mathrm{cm}^{3}$, and steel fibres $7.85 \mathrm{~g} / \mathrm{cm}^{3}$. The silica fume, added in form of powder, had a specific surface of $15-30 \mathrm{~m}^{2} / \mathrm{g}$.

Table 1 shows the PC and HPFRC (DS1\% and DS2\%) composition for $1 \mathrm{~m}^{3}$ of concrete batch used in the experimental program. Plain concrete was designed for a 28-day cubic strength of $80 \mathrm{MPa}$.

The experimental compressive strength varied between 79.2 $\mathrm{MPa}$ and 81.0 MPa.

In order to obtain a cohesive and flowable mixture and a uniform fibre distribution, a well-defined mixing procedure was performed. The sample preparation is given elsewhere [6]. All the test specimens were removed from the moulds within 24 hours and cured for 27 more days under water saturated sand.

3.3. Instrumentation and Test Procedure. The compressive strength tests were carried out after 28 days from cast on $150 \mathrm{~mm}$ cubes, according to UNI EN 12390-3 [21]. A Zwick/Roell servo hydraulic closed-loop test machine with a capacity of $3000 \mathrm{kN}$ was used. The bending tests were performed after 28 days from cast on $150 \times 150 \times 600 \mathrm{~mm}$ prismatic specimens. At the midspan of the specimens, a single notch was sawn with a diamond blade to localize the crack, with a depth of $25 \mathrm{~mm}$, according to EN 14651 [15], 


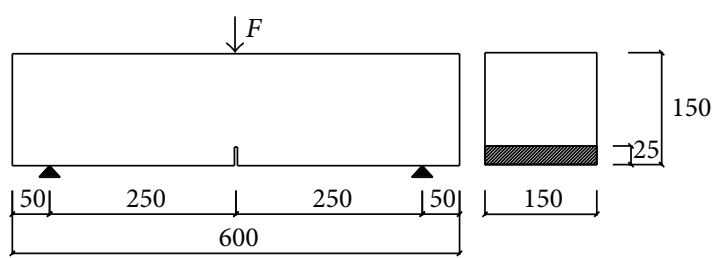

(a) Specimen dimensions

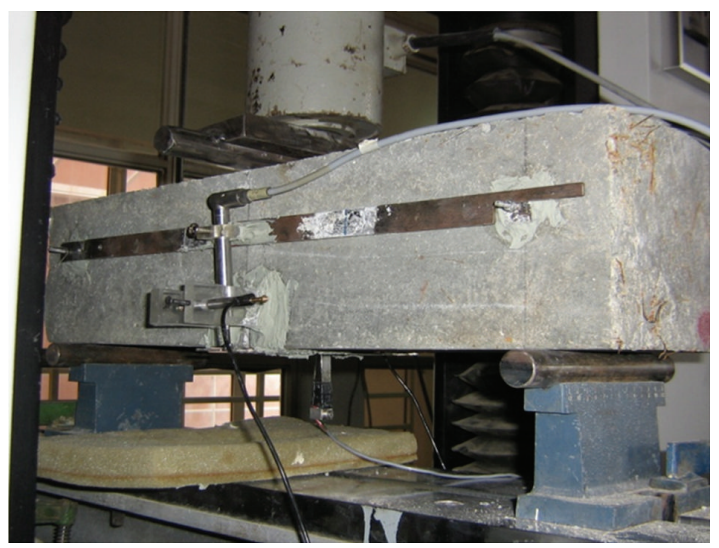

(b) Experimental test setup

FIgURE 1: Three-point bending test.

or a depth of $45 \mathrm{~mm}$, according to UNI 11039-2 [11]. The specimens dimensions and the test setup required by the two standards are shown in Figures 1 and 2. In these figures, the total applied load is labelled with the letter $F$, in the case of three-point bending test according to EN 14651 [15], and with the letter $P$ in the case of four-point bending test according to UNI 11039-2 [11]. The tests were carried out by imposing a displacement rate of $0.05 \mathrm{~mm} / \mathrm{min}$. A $100 \mathrm{kN}$ type C1 HBM load cell was mounted on an INSTRON 1195 electromechanical testing machine. Two or four WA20 HBM linear variable displacement transducers (LVDTs) inductive displacement transducers were used to measure the vertical displacement under the load point on the two specimen faces. The transducers were fixed on a rigid yoke accurately mounted on the specimen in order to minimize the effect of rotation during the test. Furthermore, two WI10 HBM LVDTs were placed at the tip notch on the two faces of the specimens to measure the crack tip opening displacement (CTOD). The crack mouth opening displacement (CMOD) was measured by a TML resistive full bridge transducer astride the notch. The data acquisition and signal control were carried out by using an HBM Spider 8 control unit. The experimental setup used to carry out the three-point bending tests is shown in Figure 1(b), while the one used in the case of four-point bending tests is shown in Figure 2(b).

\section{Evaluation of Test Results}

4.1. Behaviour in Compression. The cube compressive peak strength of each tested specimen and the mean value of the compressive strength are given in Table 2. It can be noticed that the cube compressive peak strength is not substantially

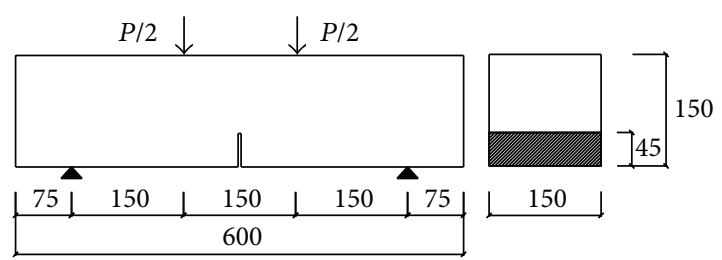

(a) Specimen dimensions

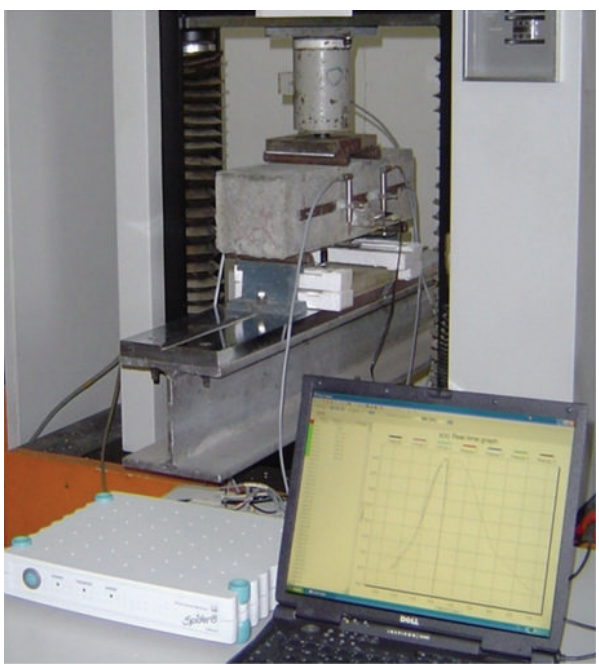

(b) Experimental test setup

FIGURE 2: Four-point bending test.

TABLE 2: Cube compressive strength.

\begin{tabular}{lcc}
\hline Specimens & Strength $(\mathrm{MPa})$ & Mean value $(\mathrm{MPa})$ \\
\hline PC_1 & 80.2 & \\
PC_2 & 81.0 & 80.1 \\
PC_3 & 79.2 & \\
\hline DS1\%_1 & 82.7 & 80.5 \\
DS1\%_2 & 80.7 & \\
DS1\%_3 & 78.2 & \\
\hline DS2\%_1 & 78.4 & 78.2 \\
DS2\%_2 & 76.0 & \\
DS2\%_3 & 80.2 &
\end{tabular}

influenced by the addition of steel fibres. This result was made possible because all specimens (PC and HPFRC) were made from mixes with the same fineness modulus; the effect of the addition of fibres to the compressive peak strength was negligible.

4.2. Peak Load and Deflections in the Bending Tests. The behaviour of the ordinary concrete specimens was almost linear-elastic up to the peak load, followed by a slight descending branch up to failure, and then, the complete separation of specimens into two parts occurred. PC specimens subjected to three-point bending tests exhibited the same brittle behaviour as observed in the four-point bending tests.

On the contrary, HPFRC specimens showed a trilinear variation with an extensive cracking process between the first 
TABLE 3: Three-point bending tests: peak loads and corresponding stresses.

\begin{tabular}{lcc}
\hline Specimens & $\begin{array}{c}\text { Peak load } \\
\mathrm{kN}\end{array}$ & $\begin{array}{c}\text { Peak stress } \\
\mathrm{MPa}\end{array}$ \\
\hline PC_1 & 18.7 & 6.0 \\
PC_2 & 17.4 & 5.6 \\
PC_3 & 17.3 & 5.5 \\
Mean value & 17.8 & 5.7 \\
DS1\%_1 & 43.8 & 14.0 \\
DS1\%_2 & 42.4 & 13.6 \\
DS1\%_3 & 30.8 & 9.9 \\
Mean value & 39.0 & 12.5 \\
DS2\%_1 & 49.5 & 15.8 \\
DS2\%_2 & 47.7 & 15.3 \\
DS2\%_3 & 46.1 & 14.8 \\
Mean value & 47.8 & 15.3 \\
\hline
\end{tabular}

TABLE 4: Four-point bending tests: peak loads and corresponding stresses.

\begin{tabular}{lcc}
\hline & Peak load $(\mathrm{kN})$ & Peak stress $(\mathrm{MPa})$ \\
\hline PC_1 & 16.4 & 4.5 \\
PC_2 & 13.5 & 3.7 \\
PC_3 & 17.3 & 4.7 \\
Mean value & 15.7 & 4.3 \\
DS1\%_1 & 46.0 & 12.5 \\
DS1\%_2 & 50.4 & 13.7 \\
DS1\%_3 & 47.3 & 12.9 \\
Mean value & 47.9 & 13.0 \\
DS2\%_1 & 84.2 & 22.9 \\
DS2\%_2 & 80.9 & 22.0 \\
DS2\%_3 & 67.7 & 18.4 \\
Mean value & 77.6 & 21.1
\end{tabular}

crack load and the peak load that clearly differentiated them from the PC specimens. In the region near the maximum load, there was a stable crack propagation due to the effect of the fibres on the ligament surface. After reaching the peak load, load decay occurred depending on the amount of steel fibres on the fracture surface. As microcracks grew towards larger macrocracks, the use of long hooked end fibres with high aspect ratio became more active in the crack bridging actions. The typical experimental load-CMOD, load-CTOD, and load-deflection $(\delta)$ curves of the HPFRC specimens are shown in Figure 3. The CTOD given here is the average value between the front and the rear measurements.

The comparison of the curves obtained according the two different standard procedures highlights that HPFRC specimens with $1 \%$ of fibre content subjected to four-point bending tests showed the same performance of HPFRC specimens with $2 \%$ of fibre content subjected to threepoint bending tests in terms of peak load and descending branch, while the specimens subjected to three-point bending tests showed more extended deflections compared to the specimens subjected to four-point bending tests. The peak
TABLE 5: Peak loads and strength factors for three-point and fourpoint bending tests.

\begin{tabular}{lccccc}
\hline $\begin{array}{l}\text { Bending test } \\
\text { (mean values) }\end{array}$ & $\mathrm{PC}$ & $1 \%$ & S.F. & $2 \%$ & $\begin{array}{c}\text { S.F. } \\
\mathrm{kN}\end{array}$ \\
\hline Three-point & 17.8 & 39.0 & 2.19 & 47.8 & 2.69 \\
Four-point & 15.7 & 47.9 & 3.05 & 77.6 & 4.94 \\
\hline
\end{tabular}

loads of the HPFRC specimens increase with the increase of steel fibre volume content. Specifically, for HPFRC with $1 \%$ and $2 \%$ of fibre volume content, the maximum load is about two and three times higher, respectively, compared to that of PC for specimens subjected to three-point bending tests (Table 3), while it is about three and five times higher for specimens subjected to four-point bending tests (Table 4).

The mean value of the peak load and the strength factors (S.F.) evaluated for all specimens is given in Table 5 for both three-point and four-point bending tests.

Once the peak load is reached, load carrying capacity decays, with a greater amplitude if the number of the fibres on the fracture surface is lesser.

The residual load evaluated at a CTOD value of $3 \mathrm{~mm}$ is about $73 \%$ and $79 \%$ of the peak load for a volume content of steel fibres of $1 \%$ and $2 \%$, respectively, in the case of threepoint bending tests, and it is about $89 \%$ and $90 \%$ for $1 \%$ and $2 \%$ of steel fibre content, respectively, of their peak load, in the case of four-point bending tests (see Figure 3). The higher residual forces at a greater deflection value is due to the presence of the hooked end fibres with a long embedded length. In fact, both these aspects provide higher pull out force at larger crack widths.

4.3. EN 14651 (2007). With reference to the curves experimentally recorded, the load at the limit of proportionality, $F_{L}$, the corresponding strength, $f_{\mathrm{ct}, L}^{f}$, and the residual flexural strengths, $f_{R, j}$, were evaluated according to EN 14651 [15].

According to this recommendation, the load at the limit of proportionality $\left(F_{L}\right)$ is equal to the highest value of the load recorded up to CMOD value of $0.05 \mathrm{~mm}$, and the strength corresponding to the limit of proportionality (LOP) can be computed using the following expression:

$$
f_{\mathrm{ct}, L}^{f}=\frac{3 \cdot F_{L} \cdot l}{2 \cdot b \cdot h_{\mathrm{sp}}^{2}}(\mathrm{MPa}),
$$

where $b(150 \mathrm{~mm}), h_{\mathrm{sp}}(125 \mathrm{~mm})$, and $l(500 \mathrm{~mm})$ are the width, the distance between the tip of the notch and the top of the specimen, and the span of the specimen, respectively.

The residual flexural tensile strengths $f_{R, 1}, f_{R, 2}, f_{R, 3}$, and $f_{R, 4}$ at the CMOD value of $0.5 \mathrm{~mm}, 1.5 \mathrm{~mm}, 2.5 \mathrm{~mm}$, and $3.5 \mathrm{~mm}$ (Figure 4) were also computed. In general, the residual flexural strength $f_{R, j}$ is given by the following expression:

$$
f_{R, j}=\frac{3 \cdot F_{R, j} \cdot l}{2 \cdot b \cdot h_{\mathrm{sp}}^{2}}(\mathrm{MPa}) .
$$




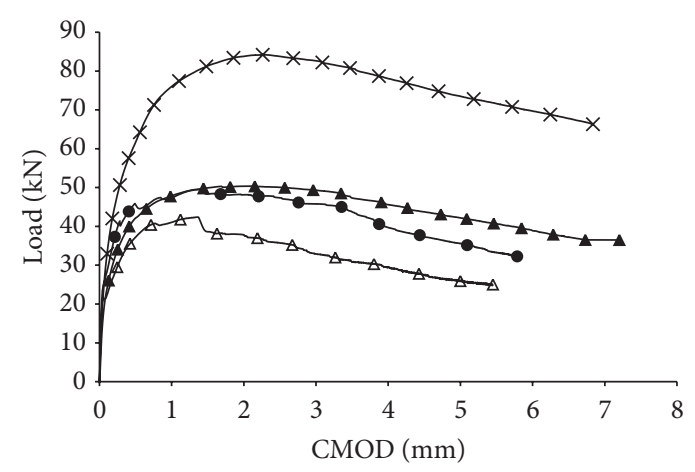

3-point bending test $\triangle \mathrm{DS} 1 \%$

- DS2\% 4-point bending test

- DS $1 \%$

$\times$ DS $2 \%$

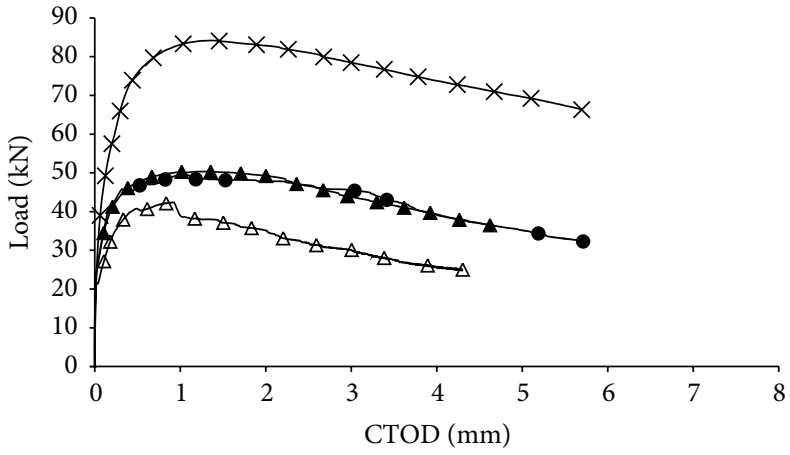

3-point bending test $\triangle \mathrm{DS} 1 \%$

- DS2\% 4-point bending test

- DS $1 \%$

$\times \mathrm{DS} 2 \%$

(a)

(b)

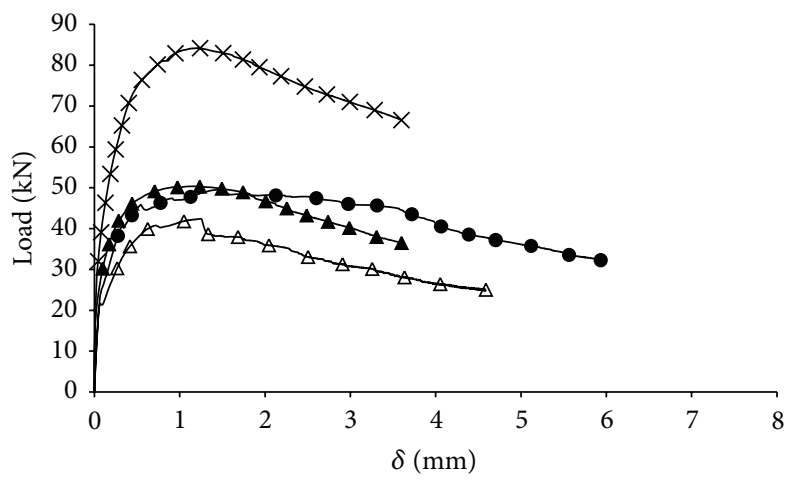

3-point bending test

$\triangle \mathrm{DS} 1 \%$

- DS2\% 4-point bending test

- DS $1 \%$

$\times \mathrm{DS} 2 \%$

(c)

FIgURE 3: Typical experimental curves: (a) load-CMOD; (b) load-CTOD; (c) load-deflection.

All these expressions were defined assuming a linear stress distribution on the cross section. The results are all reported in Table 6 .

In case of testing machine controlling the rate of increase of deflection, the European Committee suggests that the CMOD related parameters are transformed into deflection related parameters. The relation between CMOD and deflection may be approximated by

$$
\delta=0.85 \cdot \mathrm{CMOD}+0.04(\mathrm{~mm})
$$

$f_{R, 1}$ can be used in the verification of the serviceability limit states, while $f_{R, 4}$ is applied in the ultimate limit state analysis.

The strengths at the limit of proportionality reach similar values, and they are not affected by the increase of fibre volume content, while the residual strengths, $f_{R, 1}, f_{R, 2}, f_{R, 3}$, and $f_{R, 4}$ increase of about $23 \%, 31 \%, 42 \%$ and $50 \%$, respectively, for specimens with $2 \%$ of fibre volume content compared to the specimens with $1 \%$ of fibre volume content. This highlights that the volume content of steel fibres contributes mainly on the post-peak behaviour (Table 6).
TABLE 6: Three-point bending tests: tensile strength parameters.

\begin{tabular}{lcccccc}
\hline & $F_{L}$ & $f_{\mathrm{ct}, L}^{f}$ & $f_{R, 1}$ & $f_{R, 2}$ & $f_{R, 3}$ & $f_{R, 4}$ \\
& $\mathrm{kN}$ & $\mathrm{MPa}$ & $\mathrm{MPa}$ & $\mathrm{MPa}$ & $\mathrm{MPa}$ & $\mathrm{MPa}$ \\
\hline DS1\%_1 & 30.2 & 9.7 & 13.8 & 12.6 & 11.6 & 10.7 \\
DS1\%_2 & 21.5 & 6.9 & 11.8 & 12.4 & 11.4 & 9.8 \\
DS1\%_3 & 19.1 & 6.1 & 8.0 & 9.7 & 7.1 & 5.4 \\
Mean value & 23.6 & 7.6 & 11.2 & 11.6 & 10.0 & 8.6 \\
DS2\%_1 & 24.7 & 7.9 & 14.1 & 15.7 & 15.4 & 14.7 \\
DS2\%_2 & 24.2 & 7.7 & 13.7 & 15.1 & 14.3 & 13.1 \\
DS2\%_3 & 23.5 & 7.5 & 13.5 & 14.7 & 13.0 & 11.0 \\
Mean value & 24.1 & 7.7 & 13.8 & 15.2 & 14.2 & 12.9 \\
\hline
\end{tabular}

4.4. UNI 11039-2 (2003). According to UNI 11039-2 [11], the following parameters have to be evaluated to describe the post-cracking behaviour of HPFRC materials: the first crack load $\left(P_{\text {If }}\right)$, the first crack nominal strength $\left(f_{\text {If }}\right)$, the equivalent strengths $\left(f_{\text {eq }(0-0.6)}, f_{\text {eq( }(0.6-3)}\right)$, and the ductility indexes $\left(D_{0}, D_{1}\right)$. 


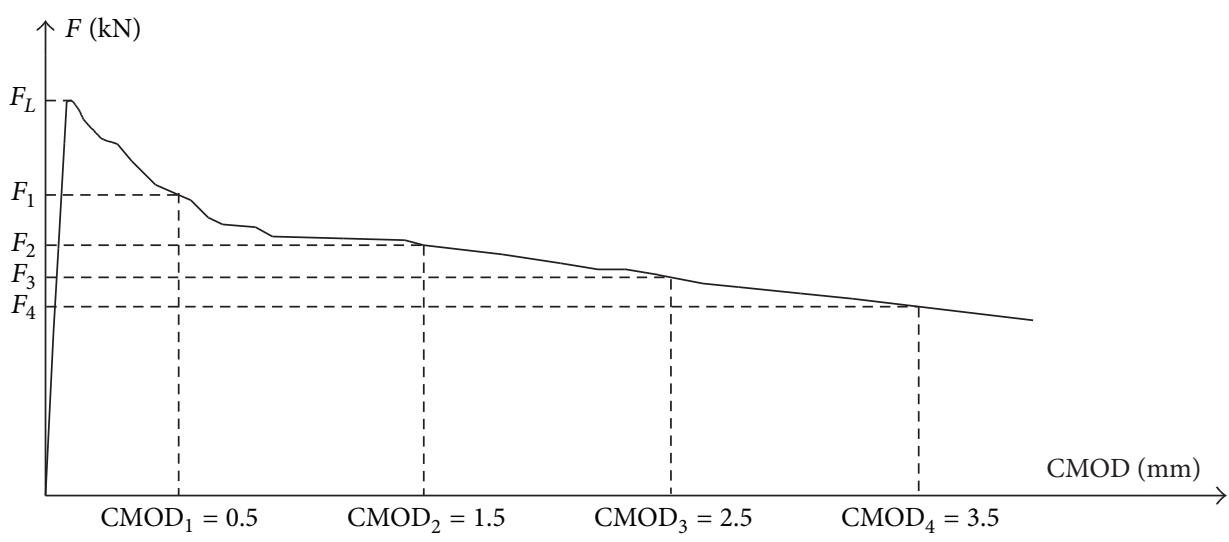

FIgUre 4: Typical load-CMOD curve from EN 14651 (2007).

The first crack nominal strength represents the matrix behaviour and can be computed using this expression:

$$
f_{\mathrm{If}}=\frac{P_{\mathrm{If}} \cdot l}{b \cdot\left(h-a_{0}\right)^{2}}(\mathrm{MPa}),
$$

where $b(150 \mathrm{~mm}), h(150 \mathrm{~mm})$, and $l(450 \mathrm{~mm})$ are the width, the height, and the span of the specimen, respectively, and $a_{0}(45 \mathrm{~mm})$ is the height of the notch, and $P_{\text {If }}$ corresponds to the value of the load recorded for a crack tip opening displacement equal to $\mathrm{CTOD}_{0}$; the latter is the CTOD corresponding to the peak load of a reference PC specimen (mean value).

The parameters $f_{\mathrm{eq}(0-0.6)}$ and $f_{\mathrm{eq}(0.6-3)}$ are the average nominal stresses in the CTOD range between 0 and $0.6 \mathrm{~mm}$ and in the range between $0.6 \mathrm{~mm}$ and $3 \mathrm{~mm}$, respectively. These two parameters are the post-cracking equivalent strength useful for the serviceability limit state and for the ultimate limit state, respectively.

These parameters can be computed by using the following expressions:

$$
\begin{aligned}
& f_{\mathrm{eq}(0-0.6)}=\frac{l}{b \cdot\left(h-a_{0}\right)^{2}} \cdot \frac{U_{1}}{0.6}, \\
& f_{\mathrm{eq}(0.6-3)}=\frac{l}{b \cdot\left(h-a_{0}\right)^{2}} \cdot \frac{U_{2}}{2.4},
\end{aligned}
$$

where $U_{1}$ and $U_{2}$ can be evaluated as (Figure 5):

$$
\begin{aligned}
& U_{1}=\int_{0}^{0.6} P(\mathrm{CTOD}) d(\mathrm{CTOD}), \\
& U_{2}=\int_{0.6}^{3} P(\mathrm{CTOD}) d(\mathrm{CTOD}) .
\end{aligned}
$$

The ductility indexes can be calculated by the following equations:

$$
\begin{aligned}
& D_{0}=\frac{f_{\mathrm{eq}(0-0.6)}}{f_{\text {If }}}, \\
& D_{1}=\frac{f_{\mathrm{eq}(0.6-3)}}{f_{\mathrm{eq}(0-0.6)}} .
\end{aligned}
$$

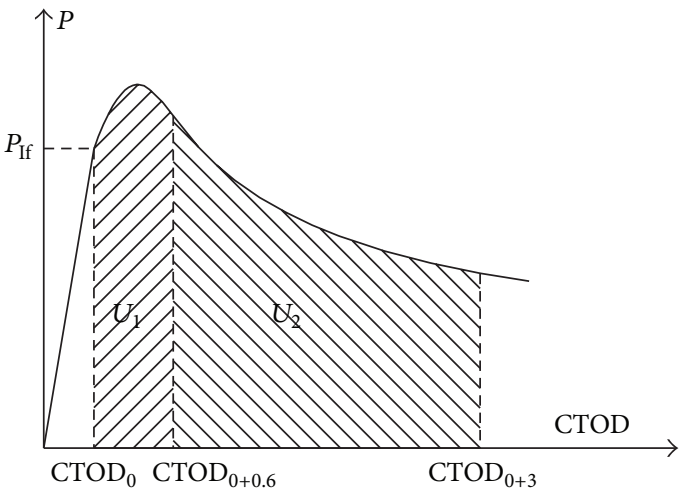

Figure 5: Typical load P-CTOD curve from UNI 11039-2 (2003).

TABLE 7: Four-point bending tests: tensile strength parameters.

\begin{tabular}{lcccccc}
\hline & $\begin{array}{c}P_{\text {If }} \\
\mathrm{kN}\end{array}$ & $\begin{array}{c}f_{\text {If }} \\
\mathrm{MPa}\end{array}$ & $\begin{array}{c}f_{\text {eq(0-0.6) }} \\
\mathrm{MPa}\end{array}$ & $\begin{array}{c}f_{\text {eq }(0.6-3)} \\
\mathrm{MPa}\end{array}$ & $\begin{array}{c}D_{0} \\
-\end{array}$ & $\begin{array}{c}D_{1} \\
\end{array}$ \\
\hline DS1\%_1 & 26.3 & 7.2 & 10.5 & 12.0 & 1.5 & 1.1 \\
DS1\%_2 & 24.6 & 6.7 & 11.6 & 13.2 & 1.7 & 1.1 \\
DS1\%_3 & 24.7 & 6.7 & 11.1 & 12.3 & 1.7 & 1.1 \\
Mean value & 25.2 & 6.9 & 11.1 & 12.5 & 1.6 & 1.1 \\
DS2\%_1 & 25.6 & 7.0 & 17.4 & 22.3 & 2.5 & 1.3 \\
DS2\%_2 & 26.3 & 7.2 & 16.0 & 21.2 & 2.2 & 1.3 \\
DS2\%_3 & 25.6 & 7.0 & 15.3 & 17.4 & 2.2 & 1.1 \\
Mean value & 25.8 & 7.1 & 16.2 & 20.3 & 2.3 & 1.2 \\
\hline
\end{tabular}

These indexes are the slope of the descending branch of the load-CTOD curve that represents the brittleness of the material. All these expressions were defined assuming a linear stress distribution on the cross section. The above parameters are given in Table 7 .

The loads/strengths at first crack reach similar values with the increase of fibre volume content. The equivalent strengths, $f_{\text {eq }(0-0.6)}$ and $f_{\text {eq }(0.6-3)}$, and the ductility indexes, $D_{0}$ and $D_{1}$, increase of about $46 \%$ and $62 \%$ and of about $44 \%$ and $9 \%$, respectively, for specimens with $2 \%$ and $1 \%$ of fibre volume content (Table 7). 


\section{Three-Point versus Four-Point Bending Tests}

The most common test used for evaluating the mechanical and fracture properties of HPFRC in mode I crack propagation is the bending test. Different configurations of bending test and different specimen geometry are proposed by the current standards. By varying the distribution of the load on the specimen and by varying the geometry of the specimen, the stress redistribution in the midspan section varies as well. The latter plays a critical role in the evaluation of the test results and consequentially in the definition of the parameters that can be used in the design of HPFRC members with conventional steel reinforcements.

In the case of three-point bending tests, in the midspan zone of the specimens, subjected to maximum bending and shear, the fracture process is influenced by a wedge diffusion of the applied load. The uncoupling of bending and shear is generally assumed for the specimens subjected to fourpoint bending test, in the central region between the applied loads, being the fracture process negligibly influenced by local effects due to load diffusion. However, the presence of the notch in the midspan section modifies the stress pattern, and shear stresses are not irrelevant in the central zone.

The experimental data highlight some important points. Firstly, the notched PC specimens subjected to four-point bending tests show flexural peak stresses which are consistently lower than those obtained in three-point bending tests, whereas for notched HPFRC specimens, the reverse is true (Tables 3, 4, and 5).

Specifically, the results on PC specimens lead to peak load values for four-point bending tests lower than threepoint bending tests of about $12 \%$. The peak stress values, computed according to a simple elastic analysis considering the different geometry of the two types of tests, are lower of about $25 \%$. This is due to the effect of the point load prevailing in the three-point bending tests. The resulting increase in the internal lever arm, along critical cross section, stands as the reason for the increased nominal stress. These considerations are not confirmed for the HPFRC specimens. For the specimens with $1 \%$ of fibre content (DS1\%), the difference is very slight. The specimens subjected to threepoint bending tests show peak stress values which are lower of about $4 \%$ than those obtained from the four-point bending tests. While for specimens with $2 \%$ of fibre volume content (DS2\%), the difference is of about $27 \%$.

The experimental curves of the same type of HPFRC specimens detected during the bending test, performed according to the EN 14651 [15] and to the UNI 11039-2 [11], have similar shapes. The curves recorded during the four-point bending tests are more stable compared to those of threepoint bending tests. The curves of the HPFRC specimens with $1 \%$ and $2 \%$ of fibre volume fraction, recorded during the three-point bending tests, show in general peak and postpeak stress values that are lower than those reached during the four-point bending tests. In fact, the residual stresses evaluated at a CTOD value of $3.00 \mathrm{~mm}$ with reference to the typical curves recorded during the three-point bending tests are lower of about $20-30 \%$, respectively, than those recorded during the four-point bending tests, for HPFRC specimens with $1 \%$ and $2 \%$ of fibre volume content (Figure 3 ).

The results obtained allow to compute the fracture energy directly as the area under the load-deflection curve or indirectly from the load-crack opening displacement curve up to a value that limits the long softening branch and through a suitable model for the kinematics of the bent beam. The area under the load-deflection curve evaluated referring to a limit displacement value of $3.00 \mathrm{~mm}$ recorded during three-point bending tests is lower of about $20-40 \%$ than that obtained by four-point bending tests. This means that fourpoint bending tests lead to higher values of fracture energy than those obtained using three-point bending tests results.

From a design point of view, the evaluation of flexural strengths parameters from these bending tests is important. The main differences between the two standards, the European EN 14651 [15] and the UNI 11039-2 [11], concern the determination of the first crack point, the way of using the post-cracking response to evaluate the equivalent/residual strengths within ranges of practical interest.

A main test parameter is the first crack that is the point on the load-deflection or load-CTOD curve at which the shape of the curve first becomes nonlinear. It approximately corresponds to the onset of cracking in the concrete matrix. Beyond this point, the fibres become more active to reduce the crack opening. According to EN 14651 [15], the first crack point corresponds to the maximum load recorded in the range between 0.00 and $0.05 \mathrm{~mm}$ of CMOD. In this study, the first crack point matches the $0.05 \mathrm{~mm}$. It is important to underline that it is a similar approach to the one proposed by the RILEM TC 162-TDF [8]. According to the RILEM indication, the first crack point corresponds to the maximum load recorded in the range between 0.00 and $0.05 \mathrm{~mm}$ of the deflection. The range proposed in both cases is arbitrary, and scientific considerations are not available. According to UNI 11039-2 [11], the first crack point of the HPFRC specimens can be joined to the crack of the concrete matrix. So, it can be assumed that the first crack arises when the extreme tensile concrete fibre at the tip of the mouth reaches the maximum tensile strain. It is possible to evaluate directly, on three PC notched specimens, the value of $\mathrm{CTOD}_{0}$ as the mean value of the CTOD measured during the four-point bending tests that corresponds to the maximum load. In the case studied, the value of $\mathrm{CTOD}_{0}$ assumed is $0.023 \mathrm{~mm}$. It is also possible to evaluate $\mathrm{CTOD}_{0}$ indirectly, assuming the value of $25 \mu \mathrm{m}$. Despite these two different procedures, the first crack strengths evaluated according to the standard UNI 11039-2 [11] $\left(f_{\text {If }}\right)$ and to the European standard EN 14651 [15] $\left(f_{\mathrm{ct}, L}^{f}\right)$ lead to similar values. The European standard showed a higher value of about $10 \%$ compared to the UNI standard.

The European standard proposes the concept of residual strength to evaluate the post-cracking response. This method has the advantage of being easier to evaluate, but it is also more susceptible to the irregularities of the load-deflection relationship recorded during the tests. On the other hand, the standard UNI 11039-2 [11] proposes the concept of equivalent strength to evaluate parameters that are used to define 
the stress-strain constitutive law proposed for modeling the HPFRC post-cracking behaviour.

The consistency of the experimental curves recorded during the bending tests shows that the fibre concrete mixtures designed and manufactured in this study were all highly cohesive without fibre bundling and fibre segregation. Concrete reinforced with steel fibre with high aspect ratio and high fibre volume content requires a high quality control to produce materials with consistent quality.

In the case of plain concrete, a brittle failure occurred by separating the elements into two parts (Figure 6), while HPFRC specimens showed a more ductile behaviour. Generally, during the tests, a main crack started at the tip of the notch uniformly on the two faces of the specimens (Figure 7). As expected, the HPFRC notched specimens were bent, and brittle failure by breaking in two parts the specimens did not occur. In fact, the fibres on the fracture surface bridged the cracks and linked the two parts of the element. This highlighted, for this type of material, the presence of a fictitious crack.

\section{Conclusions}

The following major conclusions can be drawn from this study.

(i) The experimental data obtained confirmed that the addition of steel fibres with high aspect ratio into a high strength concrete matrix significantly improves the post-peak behaviour.

(ii) The HPFRC specimens showed a more extended softening branch and also the slope of the descending branch decreases. Residual loads of 70\%-90\% of their peak loads at a CTOD value of $3.00 \mathrm{~mm}$ were recorded. The loss in load capacity was gradual especially for HPFRC with $2 \%$ fibre volume content.

(iii) The evaluation of the load-displacement curves of both PC and HPFRC materials proves that HPFRC contributes greatly to preserve the structural integrity and structural stability of concrete exposed to real life environments.

(iv) The comparison between three-point and four-point bending tests highlights that there is not a large difference between them. A significant point is related to the peak stresses. PC notched specimens subjected to four-point bending tests show flexural peak stresses which are slightly lower than those obtained in threepoint bending tests, whereas HPFRC specimens subjected to four-point bending tests show slightly higher stress values compared to those obtained in the threepoint bending tests.

(v) From a design point of view, first crack strength (or LOP) values, evaluated following the two standards, are close with an improvement of $10 \%$ in the value obtained according to the European standard procedure.

(vi) Although the test specimens and the HPFRC concrete composition are exactly the same, the values of the

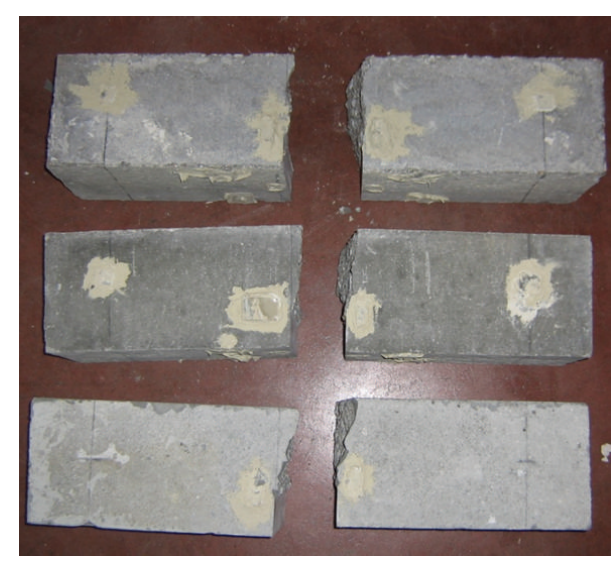

FIGURE 6: Post-test aspect of the notched specimens without fibres.

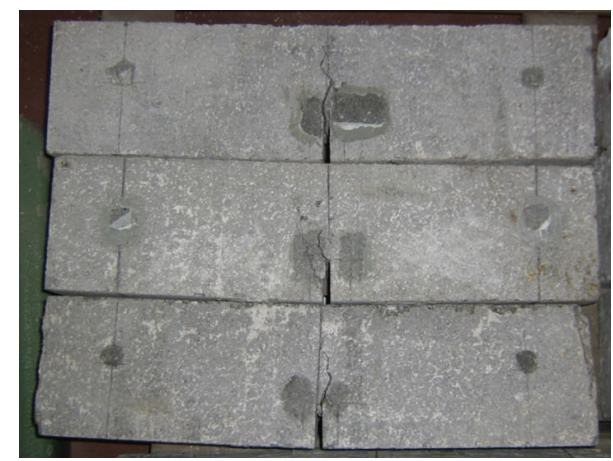

FIGURE 7: Post-test aspect of the notched specimens with $1 \%$ of steel fibres volume content.

mechanical parameters obtained from the two types of test are quite different, and a notable variation in the "load-deflection," "load-CMOD," and "loadCTOD" curves is observed in all the HPFRC specimens, both with $1 \%$ and with $2 \%$ of fibre volume.

(vii) The ductility indexes, $D_{0}$ and $D_{1}$, increase of about $46 \%$ and $62 \%$ and of about $44 \%$ and $9 \%$, respectively, for specimens with $2 \%$ and $1 \%$ of fibre volume content.

(viii) The fracture energy evaluated in the three-point bending tests is lower of about $20 \%$ and $40 \%$ than that obtained by four-point bending tests, for HPFRC with $1 \%$ and $2 \%$ of fibre volume content, respectively.

\section{References}

[1] M. A. Mansur, M. S. Chin, and T. H. Wee, "Stress-strain relationship of high-strength fiber concrete in compression," Journal of Materials in Civil Engineering, vol. 11, no. 1, pp. 21-29, 1999.

[2] G. Campione and L. La Mendola, "Behavior in compression of lightweight fiber reinforced concrete confined with transverse steel reinforcement," Cement and Concrete Composites, vol. 26, no. 6, pp. 645-656, 2004. 
[3] F. Bencardino, L. Rizzuti, G. Spadea, and R. N. Swamy, "Stressstrain behavior of steel fiber-reinforced concrete in compression," Journal of Materials in Civil Engineering, vol. 20, no. 3, pp. 255-263, 2008.

[4] M. T. Kazemi, F. Fazileh, and M. A. Ebrahiminezhad, "Cohesive crack model and fracture energy of steel-fiber-reinforcedconcrete notched cylindrical specimens," Journal of Materials in Civil Engineering, vol. 19, no. 10, pp. 884-890, 2007.

[5] N. M. Long and R. Marian, "Investigation of fracture properties of steel fiber reinforced concrete," in Proceeding of the 3rd ACF International Conference, ACF/VCA, pp. 854-861, 2008.

[6] F. Bencardino, L. Rizzuti, G. Spadea, and R. N. Swamy, "Experimental evaluation of fiber reinforced concrete fracture properties," Composites B, vol. 41, no. 1, pp. 17-24, 2010.

[7] RILEM TC 162-TDF, "Test and design method for steel fibre reinforced concrete. $\sigma-\varepsilon$ design method. Recommendation," Materials and Structures, vol. 33, no. 226, pp. 75-81, 2000.

[8] RILEM TC 162-TDF, “Test and design method for steel fibre reinforced concrete. Bending test. Final recommendation," Materials and Structures, vol. 35, no. 253, pp. 579-582, 2002.

[9] RILEM TC 162-TDF, “Test and design method for steel fibre reinforced concrete. $\sigma-\varepsilon$ design method. Final recommendation," Materials and Structures, vol. 36, no. 262, pp. 560-567, 2003.

[10] UNI 11039-1, Steel Fibre Reinforced Concrete-Definitions, Classification and Designation, 2003.

[11] UNI 11039-2, Steel Fibre Reinforced Concrete-Test Method for Determination of First Crack Strength and Ductility Indexes, 2003.

[12] ASTM C 1550, Standard Test Method for Flexural Toughness of Fiber Reinforced Concrete (Using Centrally Loaded Round Panel), 2010.

[13] ASTM C 1609, Standard Test Method for Flexural Performance of Fiber-Reinforced Concrete (Using Beam with Third-Point Loading), 2010.

[14] ASTM C 1399, Standard Test Method for Obtaining Average Residual Strength of Fiber Reinforced Concrete, 2010.

[15] EN 14651, Test method for metallic fibre concrete-Measuring the flexural tensile strength (limit of proportionality (LOP), residual). European Committee for Standardization, B-1050 Brussels, September 2007.

[16] M. di Prisco, G. Plizzari, and L. Vandewalle, "Fiber reinforced concrete in the new FIB model code," in Proceedings of the 3rd fib International Congress, Gaylord National Resort, May 2010.

[17] CNR-DT 204, Guidelines for the Design, Construction and Production Control of Fiber Reinforced Concrete Structures, CNR, Rome, Italy, 2007.

[18] Fib 55. Model code 2010. Bullettin 55. First complete draft 2010.

[19] B. Parmentier, L. Vandewalle, and F. van Rickstal, "Evaluation of the scatter of the postpeak behaviour of fibre reinforced concrete in bending: a step toward reliability," in Proceeding of the 7th RILEM International Symposium on Fibre Reinforced Concrete: Design and Applications (BEFIB '08), pp. 133-143, 2008.

[20] R. Hameed, A. Turatsinze, F. Duprat, and A. Sellier, "Metallic fiber reinforced concrete: effect of fiber aspect ratio on the flexural properties," Journal of Engineering and Applied Sciences, vol. 4, no. 5, pp. 67-72, 2009.

[21] UNI EN 12390-3, Testing Hardened Concrete-Compressive Strength of Test Specimens, 2003. 

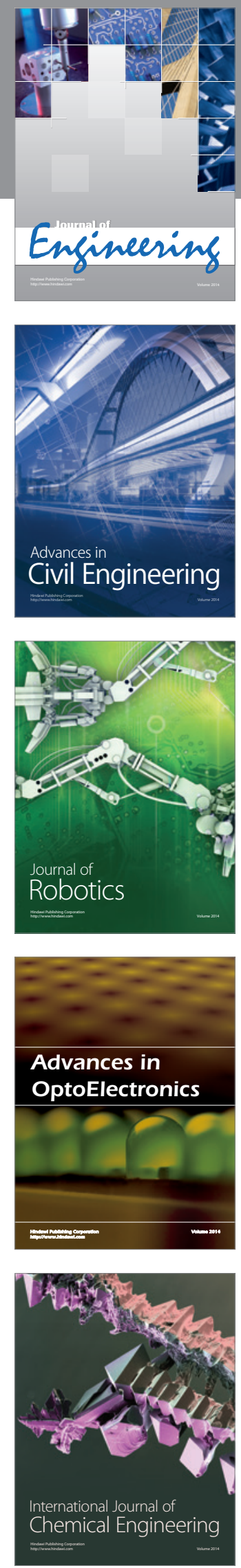

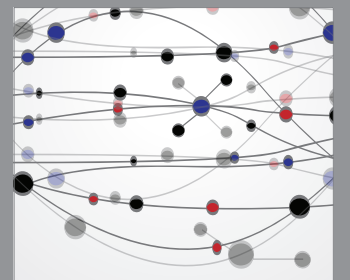

The Scientific World Journal
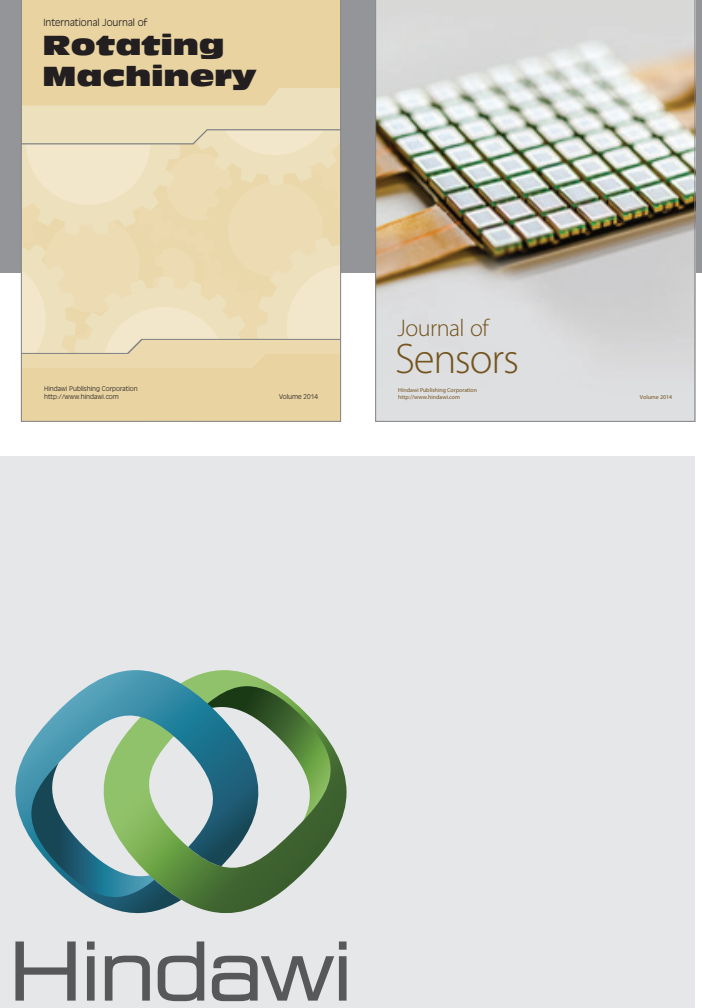

Submit your manuscripts at http://www.hindawi.com
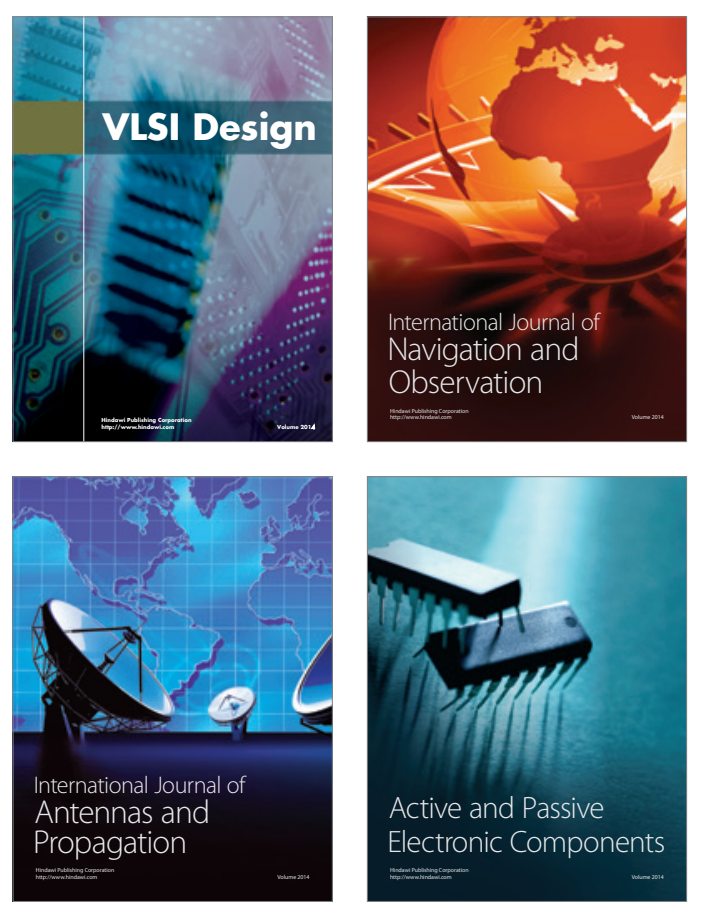
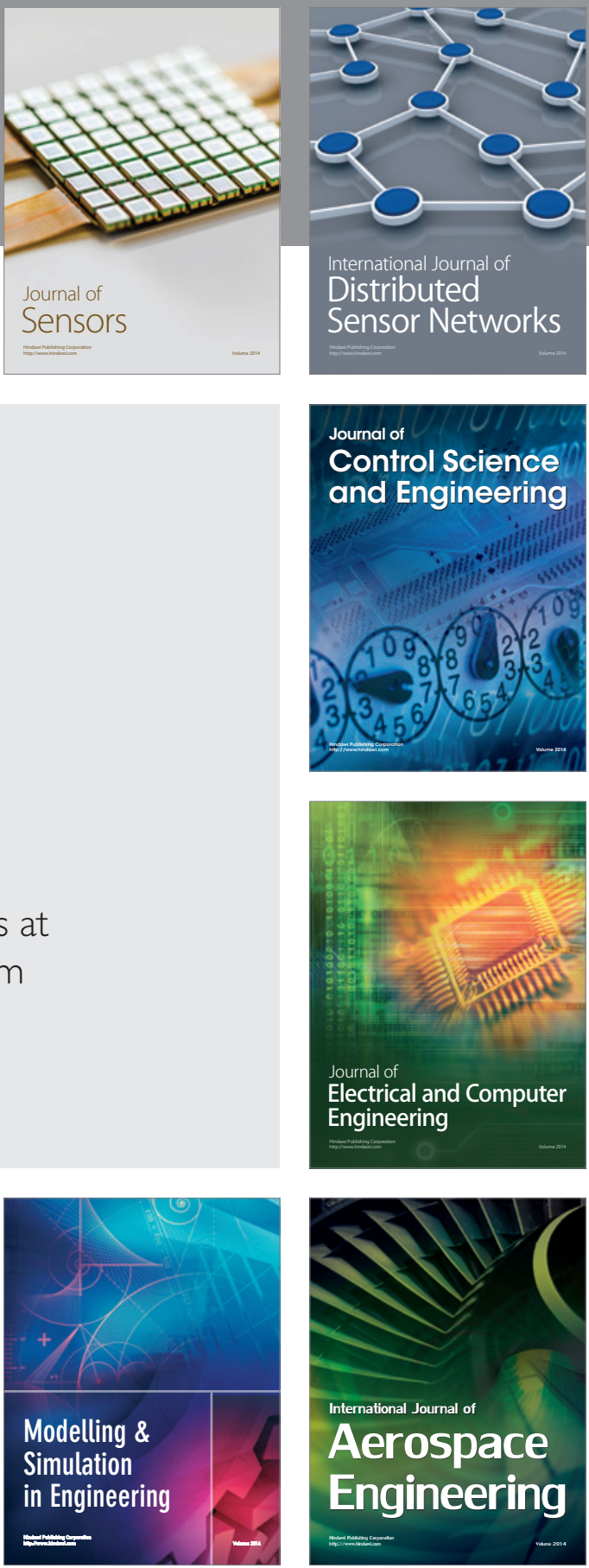

Journal of

Control Science

and Engineering
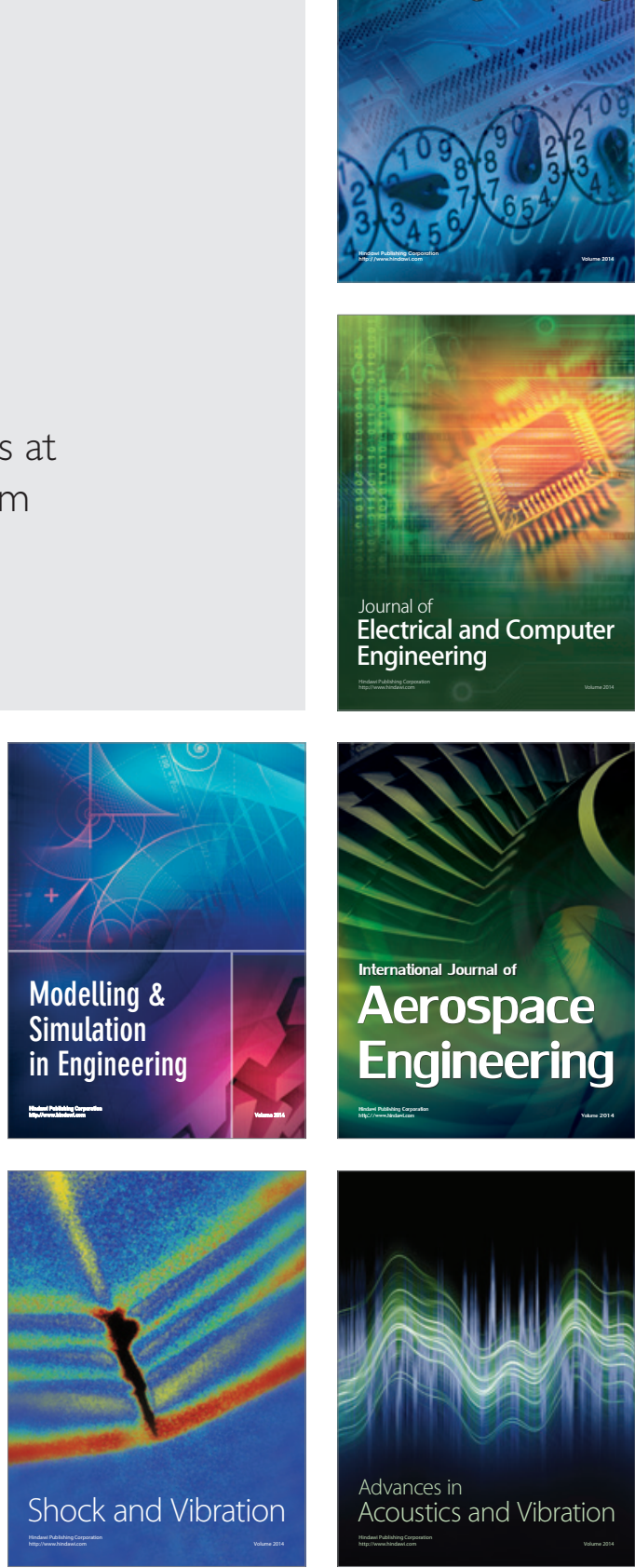